\title{
The Effects of Population Redistribution on the Level of Mortality in Nineteenth-Century England and Wales
}

\author{
ROBERT WOODS
}

It appears from Wrigley and Schofield's estimates of life expectation at birth in England during the late eighteenth and early nineteenth centuries that no radical increase occurred. ${ }^{1}$ In 1851 life expectation was approximately 40 for both sexes in combination, about 36 or 37 in 1801, and the same in 1751. At best three or four years were added during the first half of the nineteenth century, but life chances were not substantially improved during the last half of the eighteenth century. By 1901 life expectation had reached about 48 , and in 1911 it was in the low fifties and increasing rapidly as a direct result of the secular decline in infant mortality that began in the early $1900 \mathrm{~s}^{2}$ The impression given by these figures is one of no change followed by slow change and accelerating advance. But to what extent is this an illusion, an artifact of the averaging together of very different regional and local mortality patterns?

\section{THE MORTALITY SERIES}

Wrigley and Schofield's life expectation series applies only to England, and not to Wales or Monmouthshire. In the absence of civil registration before 1837 their series had of necessity to be based on parish register data, but the technique of back projection was firmly anchored to the Third English Life Table, which was estimated by William Farr from age structures provided by the 1841 and 1851 population census and age-atdeath information from the civil registration system for 1838 to $1854 .{ }^{3}$ Table 1 here compares Wrigley and Schofield's estimates of life expectation for England with those for England and Wales from the Third to the Eighth English Life Tables. The composite series has been constructed by taking three-point moving averages of the Wrigley and

Journal of Economic History, Vol. XLV, No. 3 (Sept. 1985). (O) The Economic History Association. All rights reserved. ISSN 0022-0507.

The author is a senior lecturer in the Department of Geography, University of Sheffield, Sheffield, S10 2TN, United Kingdom. Helpful comments on an earlier draft of this paper were received from David Grigg, Andy Hinde, Dick Lawton, Tony Wrigley and John Woodward. Financial assistance was received from the Nuffield Foundation and the University of Sheffield Research Fund.

' E. A. Wrigley and R. S. Schofield, The Population History of England, 1541-1871: A Reconstruction (London and Cambridge, 1981). See especially Tables 7.15 and A3.1.

2 Background issues and sources are considered in Robert Woods and John Woodward, eds., Urban Disease and Mortality in Nineteenth-Century England (London and New York, 1984). See also Jan de Vries, European Urbanization, 1500-1800 (Cambridge and London, 1984) on the causes and consequences of urbanization in the early modern period.

${ }^{3}$ The First and Second English Life Tables relate to 1841 and 1838-1844. Both employ the agestructure data from the 1841 census, which many contemporaries and modern demographers have found unreliable. See, for example, R. D. Lee and D. Lam, "Age Distribution Adjustments for English Censuses, 1821 to 1931," Population Studies, 37 (Nov. 1983), pp. 445-64. Dr. William Farr's work on the Third English Life Table for 1838-1854 marks a significant advance because it also utilizes the more reliable 1851 census age structures and age-at-death data for a longer period. See William Farr, English Life Table. Tables of Lifetimes, Annuities, and Premiums (London, 1864); also Wrigley and Schofield, Population History, pp. 708-14, on their derivation of "English" model life tables and use of English Life Table 3. 
TABLE 1

ESTIMATES OF LIFE EXPECTATION AT BIRTH FOR ENGLAND AND WALES, 1801-1911

\begin{tabular}{|c|c|c|c|c|}
\hline Year & $\begin{array}{l}\text { Wrigley } \\
\text { and } \\
\text { Schofield }\end{array}$ & $\begin{array}{c}\text { English Life } \\
\text { Tables (table } \\
\text { number in } \\
\text { parentheses) }\end{array}$ & $\begin{array}{l}\text { Three-point } \\
\text { Mean of } \\
\text { Wrigley and } \\
\text { Schofield }\end{array}$ & $\begin{array}{c}\text { Composite } \\
\text { Series }\end{array}$ \\
\hline 1796 & 36.8 & & & \\
\hline 1801 & 35.9 & & 37.1 & 37 \\
\hline 1806 & 38.7 & & 37.4 & \\
\hline 1811 & 37.6 & & 38.1 & 38 \\
\hline 1816 & 37.9 & & 38.2 & \\
\hline 1821 & 39.2 & & 39.0 & 39 \\
\hline 1826 & 39.9 & & 40.0 & \\
\hline 1831 & 40.8 & & 40.3 & 40 \\
\hline 1836 & 40.2 & & 40.4 & \\
\hline 1841 & 40.3 & & 40.0 & 40 \\
\hline 1846 & 39.6 & $40.9(3)$ & 39.8 & \\
\hline 1851 & 39.5 & & 39.8 & 41 \\
\hline 1856 & 40.4 & & 40.3 & \\
\hline 1861 & 41.2 & & 40.6 & 41 \\
\hline 1866 & 40.3 & & 40.9 & \\
\hline 1871 & 41.3 & & & 42 \\
\hline 1876 & & $43.0(4)$ & & \\
\hline 1881 & & & & 44 \\
\hline 1886 & & $45.4(5)$ & & \\
\hline 1891 & & & & 46 \\
\hline 1896 & & $46.0(6)$ & & \\
\hline 1901 & & & & 48 \\
\hline 1906 & & $50.5(7)$ & & \\
\hline 1911 & & $53.4(8)$ & & 53 \\
\hline
\end{tabular}

Notes: The derivation of the composite series is discussed in the text.

Sources: Wrigley and Schofield, Population History, p. 230; English Life Tables 3 to 6 are compared in Parts 1 and 2 of Decennial Supplement to the Sixty-Fifth Annual Report of the Registrar of Births, Deaths and Marriages (Parliamentary Papers 1905, xviii). Tables 7 and 8 appear in Part 1 of the Supplement to the Seventy-Fifth Annual Report (Parliamentary Papers 1914, xiv). English Life Table 3 applies to 1838-1854; Table 4, 1871-1880; Table 5, 1881-1890; Table 6, 1891-1900; Table 7, 1901-1910; and Table 8, 1910-1912.

Schofield series and splicing them onto the averages for adjacent pairs of life expectations from the English Life Tables. Since Life Tables 4 to 7 apply to decades this procedure yields estimates for 1881,1891 , and 1901. A certain amount of rounding has also been necessary to preserve the smooth form of the series. The calculations are based on two assumptions: first, that Wrigley and Schofield's series is reliable, and, second, that their estimates apply equally well to the whole of England and Wales. The first must remain an assumption, but it is a reasonable one; the second must be questioned. ${ }^{4}$ For Wales and Monmouthshire to have significantly affected the national

\footnotetext{
${ }^{4}$ Although The Population History of England has attracted considerable critical interest, the life expectation estimates, especially for the nineteenth century, remain relatively unscathed. See, for example, Peter H. Lindert, "English Living Standards, Population Growth, and WrigleySchofield," Explorations in Economic History, 20 (April 1983), pp. 131-55; David R. Weir, "Life Under Pressure: France and England, 1670-1870," this Journal, 44 (March 1984), pp. 27-47; and especially Jeffrey G. Williamson, "British Mortality and the Value of Life, 1781-1931," Population Studies, 38 (March 1984), pp. 157-72.
} 
mortality level that area would need to have been all rural or all urban, and thus to have had extremely low or high mortality since its population represented less than half of that living in London at mid-century. Since neither of these two extremes held, we may have confidence regarding the second assumption.

\section{POPULATION DISTRIBUTION}

We are also fortunate in having estimates of population distribution among categories of places that are likely to have significance for varying mortality conditions. ${ }^{5}$ For the purposes of illustration I shall define four categories: London; urban places containing populations of 100,000 or more, but excluding London (large towns); places with population greater than or equal to 10,000 , but less than 100,000 (small towns); and the residual rural population. Table 2 is based on Law's work and ultimately the Population Censuses of England and Wales, 1801-1911, and gives the probability of finding Englishmen or Welshmen living in four categories of places. Once again it is necessary to assume that these are reliable estimates. The first censuses were susceptible to underenumeration, but this probably became less significant at least by $1851 .{ }^{6}$ Defining categories of constant settlement size also poses problems, but most can be overcome by the manipulation of local populations.

In passing, it is worth noting the changing fortunes of these four categories. While London's share of the population remained stable, the large towns increased their proportion dramatically; the small towns more than doubled; and the rural share was reduced by over 60 percent. Urban growth and urbanization were truly dramatic, the consequences wide and various.?

\section{ESTIMATION OF MORTALITY OF POPULATION CATEGORIES}

Although it is generally necessary to estimate the category-specific life expectation at birth, firm evidence exists for 1911 , which provides a basis for earlier decades. The newly constituted local government areas of 1911 were used to construct separate life tables for London, county boroughs, urban districts, and rural districts. ${ }^{8}$ The respective life expectations were: $52,51,53$, and 55. Multiplication of these figures with the corresponding probabilities for 1911 in Table 2 gives a weighted-average life expectation for England and Wales of 52.84, which suggests that these figures for aggregations of local government areas may also be used to represent the four categories defined above. ${ }^{9}$

A further datum point is provided by other analyses of the mortality pattern in 1861 that have been based on data for registration districts. ${ }^{10}$ These small areas were used for

\footnotetext{
5 Particularly C. M. Law, "The Growth of Urban Population in England and Wales, 1801-1911," Transactions, Institute of British Geographers, 41 (1967), pp. 125-43. Law's estimates have also been used in Brian T. Robson, Urban Growth: An Approach (London, 1973); and Richard Lawton, "Urbanization and Population Change in Nineteenth-Century England," in John Patten, ed., The Expanding City (London, 1983), pp. 179-224.

"See Lee and Lam, "Age Distribution Adjustments"; but also the assumptions made in D. V. Glass, "A Note on the Under-Registration of Births in Britain in the Nineteenth Century," Population Studies, 5 (July 1951), pp. 70-88; and Michael S. Teitelbaum, The British Fertility Decline (Princeton, 1984), regarding the quality of censuses in order to check the extent of vital under-registration.

7 Richard Lawton, "An Age of Great Cities," Town Planning Review, 43 (1972), pp. 199-224.

${ }^{8}$ These are to be found in Parliamentary Papers, 1914, xiv and apply to 1911-1912.

${ }^{9}$ That is, $(0.1254 \times 52)+(0.3130 \times 51)+(0.2627 \times 53)+(0.2989 \times 55)$.

${ }^{10}$ See Woods and Woodward, Urban Disease, pp. 37-64, but also D. V. Glass, "Some Indications of Differences Between Urban and Rural Mortality," Population Studies, 17 (March 1964), pp. 263-68.
} 


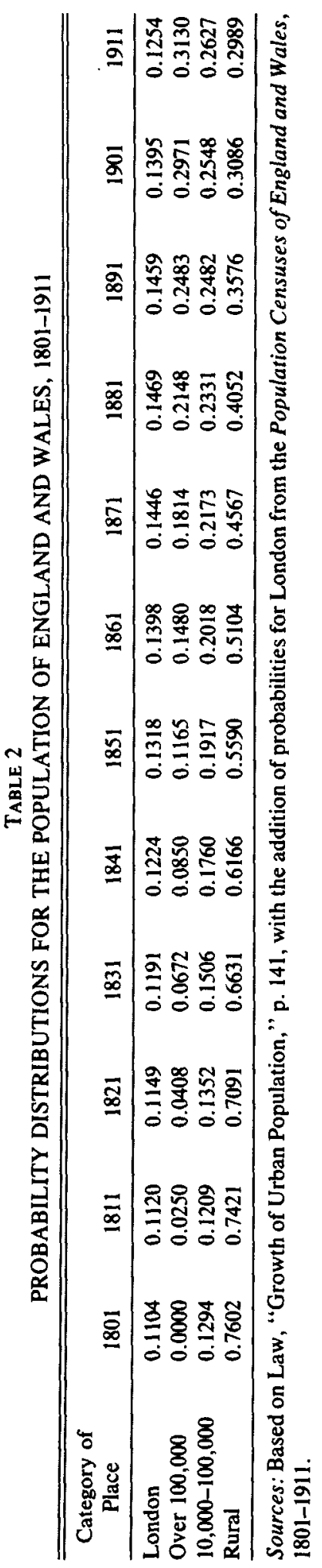


the collection and publication of vital registration statistics in England and Wales between 1837 and 1910. They were some 620 in number and they yield the framework for discerning differences between urban and rural mortality conditions. Scrutiny of the frequency distribution of the life expectations at birth by population density among registration districts in 1861 suggests that the four categories can be allocated representative life expectations of 37 (London), 35 (large towns), 40 (small towns), and 45 (rural areas). ${ }^{11}$ The national weighted average calculated in the normal way would thus be $\mathbf{4 1 . 3 9}$ compared with 41 for 1861 in the composite series (Table 1).

The remaining category-specific estimates for 1811-1911 are shown in Table $3 .^{12}$ While the weighted-average life expectation for each of the years is close to the composite series figure, it is obviously the case that the further one moves away from the 1861 and 1911 data points the greater will be the likely error. However, since nearly three-quarters of the population of England and Wales was classified as "rural" in 1811, the life expectation for that category must lie close to and above the national figure. All the estimates in Table 3 represent illustrative solutions that are consistent with the constraints outlined in Tables 1 and 2, and thus the assumptions specified above, but they are not the only solutions that could meet these constraints.

\section{IMPLICATIONS}

Much has been made of the impact of the Industrial Revolution on living standards and the quality of life in general. Table 3 gives an additional perspective: it allows us to consider the changing gradient between rural-agricultural and urban-industrial places and thus the extent to which rural to urban migration could adversely affect life chances, especially for the migrants' children. Between the rural and large-town (over 100,000) populations the difference grew wider in the first half of the nineteenth century (to a maximum of twelve years in 1831); thereafter it declined, with general convergence (to a difference of four years in 1911). Yet for each of the categories there was virtually continuous, albeit slow, improvement in mortality conditions. It was not necessary for the urban environment to deteriorate in order for mortality decline to be retarded; rapid and substantial urbanization was sufficient. ${ }^{13}$

The estimates in Table 3 also have important implications for more general explana-

\footnotetext{
11 Woods and Woodward, Urban Disease, Figure 2.14, p. 54. The relationships between life expectations for both sexes combined $(Y)$ and the population density of registration districts in persons per square kilometer $(X)$ is $Y=56.45-5.54 \log X\left(r^{2}\right.$ is 0.466 , significant at 99 percent level). $\log X$ for the large towns is greater than 3 and for the rural areas less than 2. Farr himself made equivalent calculations with death rates for 1841-1850 and 1851-1860. See Supplement to the Twenty-Fifth Annual Report of the Registrar General (Parliamentary Papers 1865, xiii) and William Farr, Vital Statistics (London, 1885), pp. 172-76.

12 Since there were no "large towns" in England and Wales in 1801 apart from London, the series were estimated from 1811 .

${ }^{13}$ This observation adds substantial weight to the points raised in the following: Peter H. Lindert and Jeffrey G. Williamson, "English Workers' Living Standards During the Industrial Revolution: A new look," Economic History Review, 2nd ser., 36 (Feb. 1983), pp. 1-25, especially section 7; Jeffrey G. Williamson, "Was the Industrial Revolution worth it? Disamenities and Death in 19th Century British Towns," Explorations in Economic History, 19 (July 1982), pp. 221-45; Jeffrey G. Williamson, Did British Capitalism Breed Inequality? (Boston, 1985), pp. 24-28; and Williamson, "British Mortality," regarding the significance of urbanization as opposed to deteriorating urban conditions, but case studies of individual towns (especially as they move between categories) may tell a different story. See, for example, W. A. Armstrong, "The Trend of Mortality in Carlisle Between the 1780s and the 1840s: A Demographic Contribution to the Standard of Living Debate," Economic History Review, 2nd ser., 34 (Feb. 1981), pp. 94-114; but also D. J. Loschky, "Urbanization and England's Eighteenth Century Crude Birth and Death Rates," Journal of European Economic History, I (Winter 1972), pp. 697-712.
} 


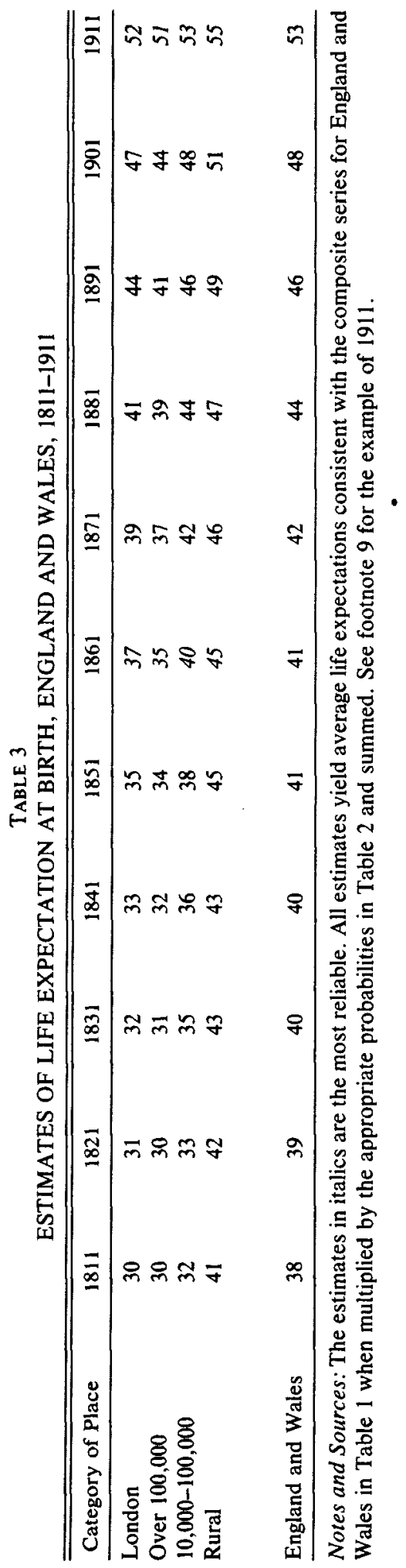


tions of mortality decline in the nineteenth century. For example, particular emphasis is given to the convergence phenomenon-that is, the faster rate of increase of life expectation in urban than rural areas-especially in the period after 1861, and the consequent reduction in urban-rural differentials. Interpretation of national trends are bound to overlook this phenomenon and thus to underplay the role of changes in the environments of large towns. ${ }^{14}$ It is also clear from Table 3 that a substantial amountas much as a third in most categories-of the increase in life expectation between 1811 and 1911 came in the last decade. This point merely serves to highlight the significance of the fall in infant mortality (which appears to date from 1900 in national vital statistics) towards the decline of overall mortality levels. The onset and timing of the secular decline in infant mortality still lacks convincing explanation, yet its substantial contribution is all too obvious. ${ }^{15}$

\footnotetext{
14 The importance of this "spatial" or "environmental" perspective is emphasized in Woods and Woodward, Urban Disease, but it is underplayed in Thomas McKeown and R. G. Record, "Reasons for the Decline of Mortality in England and Wales during the Nineteenth Century," Population Studies, 16 (July 1962), pp. 94-122; and Thomas McKeown, The Modern Rise of Population (London, 1976). The importance of that set of administrative and public health advances usually labeled the "Sanitary Revolution" appears to be reemphasized by these estimates of rural and urban life expectations.

${ }^{15}$ The main candidates in the explanation of infant mortality decline from the turn of the century are the following: the influence of the medical profession (doctors, midwives, and hospitals); maternal health and education, particularly changes in child-rearing practices; improvements in diet for mothers and infants, the practice of breast feeding, the pasteurization of milk, the purification of water; changes in living conditions and standards, especially housing and hygiene; and the use of family limitation to reduce family size and space pregnancies. Some of these possibilities have been considered: for example, see Carole Dyhouse, "Working Class Mothers and Infant Mortality in England, 1895-1914," Journal of Social History, 12 (Winter 1978), pp. 248-67; Jean Donnison, Midwives and Medical Men (London and New York, 1977); Christine Hardyment, Dream Babies (London, 1983); and M. W. Beaver, "Population, Infant Mortality and Milk," Population Studies, 27 (July 1973), pp. 243-54. But there has been no systematic analysis of all the possibilities.
} 